\title{
CONDICIONES NECESARIAS Y SUFICIENTES EN LA RESPONSABILIDAD EXTRACONTRACTUAL ${ }^{1 * *}$
}

\author{
NECESSARY AND SUFFICIENT CONDITIONS IN TORT LAW
}

\section{TONY HoNORÉ}

RESUMEN: Los argumentos sobre la causalidad dentro y fuera del ámbito del derecho usualmente dicen relación con la siguiente pregunta: ¿ debe ser la causa una condición necesaria, o una condición suficiente de un resultado, o debe ser un elemento necesario en un grupo de condiciones conjuntamente suficientes para producir un resultado? El presente ensayo defiende esta última postura tanto fuera como dentro del ámbito del derecho, siempre que se considere una secuencia de acontecimientos físicos. El artículo argumenta que no hay un significado 'jurídico' especial de causalidad, toda vez que el mismo concepto de causa se utiliza para descubrir fórmulas, para explicar acontecimientos, y para asignar responsabilidad por los resultados. Los elementos normativos son suministrados por el derecho sustantivo de la responsabilidad extracontractual, el cual define la conducta que conlleva o puede conllevar responsabilidad, y prescribe cuándo se debe probar la conexión causal entre la conducta y el daño.

Palabras clave: Causalidad, condición necesaria, conexión causal, responsabilidad extracontractual, daño, responsabilidad estricta, actividades peligrosas.

ABSTRACT: Argument about causation inside and outside the law is often concerned with the following question: Must a cause be a necessary condition of a result, a sufficient condition of the result, or a necessary element in a set of conditions jointly sufficient to produce the result? This essay supports the third view, both outside the law and inside it, whenever a sequence of physical events is in issue. The article argues that there is no special 'legal' meaning of causation, since the same concept of cause is used for discovering recipes, for explaining events, and for assigning responsibility for outcomes. The normative elements are supplied by substantive tort law, which defines the conduct that entails or may entail tort liability and prescribes when causal connection between conduct and harm must be proved.

Key words: Causation, necessary condition, causal connection, tort law, harm, strict liability, dangerous activities.

\footnotetext{
${ }^{1}$ Este texto es una traducción del artículo "Necessary and Sufficient Conditions in Tort Law", publicado originalmente en David Owen (ed.), Philosophical Foundations of Tort Law (Oxford University Press, 1995), pp. 363-85, y reimpreso en Tony Honoré, Responsibility and Fault (Hart Publishing, 1999), pp. 94-120. La traducción fue revisada por el autor y discutida con él, y cuenta con su debida autorización.

* Arturo Ibáńez León es abogado, Licenciado en Ciencias Jurídicas y Sociales de la Universidad de Chile; Magister Juris, University of Oxford; estudiante de doctorado en Derecho, University of Oxford. Alberto Pino Emhart es abogado, Licenciado en Ciencias Jurídicas y Sociales de la Universidad de Chile; Magíster en Derecho con mención en Derecho Privado, Universidad de Chile; Master of Laws, Duke University; estudiante de doctorado en Derecho, University of Oxford. Los traductores expresan toda su gratitud al profesor Honoré por su positiva acogida de esta iniciativa. Asimismo, los traductores agradecen el interés de la Revista Chilena de Derecho en la publicación y difusión de esta traducción. Los traductores asumen la responsabilidad por los errores $\mathrm{u}$ omisiones que este texto pueda contener.

* Profesor Emeritus Regius de Derecho Civil, All Souls College, University of Oxford. Se ha desempeñado como profesor en Oxford desde 1948; es el autor de dieciséis libros y tiene más de 100 artículos publicados. Entre sus libros destacan Ulpian: Pioneer of Human Rights (2a edición, Oxford University Press, 2002); Emperors and Lawyers (2a edición, Oxford Clarendon Press, 1994); Responsibility and Fault (Hart Publishing, 1999); y su obra en conjunto con HLA Hart Causation in the Law (2a edición, Oxford Clarendon Press, 1985).
} 
Los argumentos sobre la causalidad dentro y fuera del ámbito del derecho usualmente dicen relación con la siguiente pregunta: ¿¿debe ser la causa una condición necesaria, o una condición suficiente de un resultado, o debe ser un elemento necesario en un grupo de condiciones conjuntamente suficientes para producir un resultado? El presente ensayo defiende esta última postura tanto fuera como dentro del ámbito del derecho, siempre que se considere una secuencia de acontecimientos físicos. Una idea diferente pero relacionada con la anterior puede ser empleada para explicar las razones del actuar humano, utilizando las expresiones 'causar' el que las personas actúen o inducir a las personas a actuar, por sobre la idea de causar el que algo ocurra. $\mathrm{Mi}$ argumento es que no hay un significado jurídico especial de causalidad y sus conceptos relacionados, tales como la inducción.

Por otra parte, solo el derecho determina cuándo una conexión causal debe ser probada y en qué contextos legales se puede prescindir de ella. Cuando una conexión causal debe ser acreditada, el derecho también determina que se debe probar qué ha causado lo que se ha causado. Esto es especialmente importante en el ámbito de la responsabilidad extracontractual ${ }^{*}$. El sistema de responsabilidad extracontractual generalmente imputa responsabilidad por culpa a quienes por su conducta ilícita causan daño a otros; pero en algunas ocasiones el sistema impone responsabilidad estricta a personas que realizan actividades que, aunque no son ilícitas, causan daño a otros.

\footnotetext{
* Nota de los traductores: Se ha optado por traducir el término tort law como responsabilidad extracontractual por ser la traducción más cercana, sin perjuicio de que el término puede excluir algunos aspectos de lo que se denomina como tort law en los sistemas de common law.
}

La pregunta sobre causalidad adopta una forma diferente dependiendo si se trata de responsabilidad por culpa o responsabilidad estricta.

Los especialistas en responsabilidad extracontractual tradicionalmente han sostenido que cualquiera que sea el significado del concepto de conexión causal, la forma de probar si esta existe o no en un caso determinado es preguntando si, bajo las mismas circunstancias del caso, el resultado dañoso habría o no ocurrido suprimiendo el acto ilícito. Esto implica adoptar el test butfor, según el cual una conexión causal existe entre una condición y una consecuencia siempre que, de no ser por la condición, la consecuencia no habría ocurrido en las mismas circunstancias ${ }^{* *}$. El test but-for también ha sido denominado como el test de la necesidad rigurosa ${ }^{2}$. Con frecuencia el test otorga intuitivamente la respuesta correcta, pero en algunas ocasiones es deficiente. El mecanismo pretende excluir aquellos factores que no tuvieron impacto en un curso particular de acontecimientos. En este sentido, el test sirve para excluir muchas condiciones que son irrelevantes, pero también excluye otras que son relevantes ${ }^{3}$. Así, en algunos casos de sobredeterminación -situaciones en las cuales dos o más actos ilícitos independientes habrían sido por sí solos suficientes para provocar el resultado- el test but-for conduce a la dudosa con-

\footnotetext{
** Nota de los traductores: En el derecho continental, se ha utilizado el concepto de sine qua non para designar este mecanismo, pero se ha optado en la presente traducción por mantener la denominación del test but-for en su denominación en inglés, atendida la relevancia del término en la discusión de la literatura anglosajona.

2 Sobre necesidad rigurosa y débil y sobre suficiencia, véase VV. AA., Mackie (1974) pp. 39-40, 60-6, 126 7; Wright (1988) p. 1020.

3 WRIGHT (1988) p. 1022.
} 
clusión de que ninguno de los actos causó el daño. En consecuencia, si el test but-for se aplicara a tal caso, la víctima no podría obtener compensación de ninguno de los agentes del daño. Para los efectos de superar esta y otras dificultades, los tribunales han desarrollado un test alternativo de conexión causal, a ser utilizado en aquellos casos de responsabilidad extracontractual en que el test but-for parece otorgar una respuesta incorrecta. Este test alternativo pregunta si la condición en cuestión fue un factor sustancial en la producción del resultado. Pero este mecanismo, que permite a los jueces y jurados seguir sus intuiciones, es puramente pragmático $^{4}$ y no resuelve el problema teórico. La noción de factor sustancial es indefinida $-\mathrm{e}$ incluso podría considerarse indeterminada-, y difícilmente podría ser conciliada con una teoría coherente de la causalidad.

\section{LA NARRATIVA DE LA CAUSALIDAD: LOS ESFUERZOS MODERNOS PARA DESENTRAÑAR SUS MISTERIOS}

En 1959, con Herbert Hart propusimos una tesis que pensamos explicaría las bases y la justificación de nuestras intuiciones respecto a ciertos casos inusuales como los de sobredeterminación, así como los casos simples ${ }^{5}$. En ese trabajo argumentamos que para que un acontecimiento sea considerado la causa de un resultado, debe acreditarse que el evento previo es una condición causalmente relevante de ese resultado. La pregunta acerca de si es necesario algo más para convertir una condición causalmente relevante en una causa puede que-

\footnotetext{
4 Wright (1988) pp. 1018-19.

5 Hart y Honoré (1959).
}

dar pendiente en este momento; por ahora, asumamos (en contra de nuestra postura al respecto) que toda condición causalmente relevante es una causa. Nuestra teoría sostenía que un acontecimiento, como un acto ilícito previo, es causalmente relevante solo si es un elemento necesario en un grupo de condiciones que conjuntamente sean suficientes para producir la consecuencia.

Una condición puede ser necesaria solo en el sentido de constituir un elemento dentro del grupo de condiciones conjuntamente suficientes para la producción de una consecuencia. La condición es necesaria porque es requerida para completar este conjunto ${ }^{6}$.

Argumentamos que, al menos, esto es cierto para el caso de las secuencias físicas $^{7}$. Este sentido débil de 'necesario' (necesario respecto a un conjunto particular de condiciones) puede ser contrastado con el sentido riguroso de necesidad que es inherente al test but-for. Por otra parte, para el caso del concepto de 'suficiente' adoptamos su sentido riguroso. Si el conjunto de condiciones suficientes para producir la consecuencia han ocurrido, entonces la consecuencia ha ocurrido; y si la consecuencia no hubiere ocurrido, el conjunto de condiciones tampoco habría ocurrido ${ }^{8}$.

\footnotetext{
${ }^{6}$ Hart y Honoré (1959) p. 106. Una teoría diferente, aunque relacionada, era necesaria para el caso de las transacciones interpersonales.

7 Hart y Honoré (1985) pp. 51-61, 125. Véase más abajo, las notas $56-58$ y el texto que las acompaña.

8 Esto implica aplicar un test but-for a la inversa WRIGHT (1988) p. 1021 n. 108. Richard Wright denominó a una condición de estas características, necesaria en un sentido débil pero suficiente en sentido riguroso, una condición 'NESS'. Wright derivó esta idea del test NESS, que tiene como propósito reemplazar el test but-for. WRIGHT (1988) p. 1019.
} 
En 1965, John Mackie aplicó nuestra idea a regularidades causales -más bien a generalizaciones causales que a acontecimientos específicos ${ }^{9}$-. Mackie combinó esta idea con la doctrina de la pluralidad de causas. Esta última teoría plantea que en diferentes ocasiones ciertos tipos de acontecimientos -como por ejemplo la muerte o los accidentes automovilísticos- pueden tener diferentes causas. Descubrimos regularidades causales y en último término leyes causales científicas agrupando conjuntos de condiciones. Idealmente esto permitiría afirmar que una condición es un miembro necesario ${ }^{10}$ de un conjunto tal que, cuando concurren todos los miembros del conjunto, la consecuencia ineludiblemente ocurre. Las condiciones son conjuntamente suficientes para que el resultado ocurra, pero desde la perspectiva de la pluralidad de causas es posible que las condiciones no sean necesarias para dicho resultado, toda vez que pueden existir otros conjuntos de condiciones que también podrían producir la misma consecuencia ${ }^{11}$. Mackie denomina a una condición de esta naturaleza, esto es, a un miembro necesario de un grupo de condiciones conjuntamente suficientes (pero no necesarias) para producir un cierto resultado, como condición INUS (insuficiente pero necesaria parte de una condición innecesaria pero suficiente) ${ }^{*}$.

Véase más abajo las notas 16 y 17 y el texto que las acompaña.

9 Mackie (1974) pp. 59-63, desarrollando en alguna medida la idea de MArc-Wogau (1962) pp. 213-33.

10 Mackie emplea el término insuficiente (por sí mismo), lo cual es obvio pero no redundante, esto es, necesario como un elemento dentro del conjunto particular de condiciones conjuntamente suficientes. MACKIE (1974) p. 62.

${ }_{11}$ He modificado la terminología de Mackie respecto a los términos 'factor' y 'condición'.

* Nota de los traductores: la denominación INUS
Así v.gr., puede haber una regularidad causal en el hecho de que conducir imprudentemente junto con otras condiciones sean suficientes para que ocurra un accidente, y otra regularidad causal en el hecho de que conducir un vehículo a exceso de velocidad junto con otro grupo de condiciones sean suficientes para un accidente de tránsito. Si ello es así, ambas condiciones, conducir imprudentemente y conducir a exceso de velocidad, serían condiciones INUS de los accidentes de tránsito, aunque, perteneciendo a diferentes conjuntos de condiciones ${ }^{12}$, ninguna de ellas es necesaria para la producción de un accidente de tránsito.

Es importante señalar que los conjuntos de condiciones de este tipo generalmente tienen como uno de sus miembros la ausencia de condiciones contrafactuales o frustrantes. Una determinada dosis de estricnina producirá la muerte dadas ciertas condiciones fisiológicas del cuerpo, pero solo (1) en la ausencia de un antídoto y (2) en la ausencia de alguna otra causa de muerte que intervenga antes de que el veneno cause efecto. La cantidad de la dosis, las condiciones fisiológicas del cuerpo y la ausencia de un antídoto, la ausencia de alguna otra causa de muerte interviniente, etc., son todos miembros INUS de un grupo de condiciones que en conjunto son suficientes para producir la muerte.

Con algunas dudas ${ }^{13}$, Mackie concluyó que a pesar de que este análisis de

obedece a sus iniciales en inglés (Insufficient but Necessary part of an Unnecessary but Sufficient).

12 Las condiciones podrían, desde luego, pertenecer al mismo conjunto.

13 Mackie (1974) pp. 48-50 aduce buenos argumentos para concebir una causa como algo necesario y suficiente para producir su efecto, bajo las circunstancias del caso. Cfr. WRIGHT (1988) pp. 1028-9. 
regularidades causales como conjuntos de condiciones INUS con frecuencia es aplicable no solo a tipos de acontecimientos sino a acontecimientos específicos ${ }^{14}$, ello no siempre es asi ${ }^{15}$. Mackie pensaba que al menos en algunas ocasiones podemos afirmar respecto a una instancia específica de una condición, como no prestar debida atención, que dicha condición causó un accidente automovilístico, aunque no por ello nos comprometamos con alguna regularidad que consideraría el no prestar debida atención como una condición INUS de los accidentes de tránsito. No es que seamos incapaces, junto con los expertos científicos, de elaborar una generalización satisfactoria que combine en su debida proporción los factores de velocidad, posición de la víctima, visibilidad, condiciones del camino, etc. El problema es que muchas veces concluimos que de no ser por la falta de debida atención, este accidente no habría ocurrido sin creer ni siquiera en principio que esto constituye una instancia de una regularidad relativa a la velocidad, posición y condiciones del camino, entre otros factores. 'Una afirmación causal singular no necesita implicar siquiera la generalización más vaga' ${ }^{16}$. Si en un caso particular podemos respaldar nuestra convicción recurriendo a un conjunto de condiciones INUS, tanto mejor; pero ello no es esencial.

En 1985, en un importante artículo, Richard Wright manifestó su desacuerdo con la postura de Mackie respecto a este punto y, proponiendo el test NESS (Elemento Necesario de un Conjunto

\footnotetext{
14 Mackie (1974) pp. 65-6.

15 Mackie (1974) pp. 40-58

16 Mackie (1974) pp. 77-8. Criticado acertadamente por WRIGHT (1988) pp. 1031-4.
}

Suficiente) ${ }^{*}$, elaboró la idea que con Hart habíamos originalmente propuesto ${ }^{17}$. Su versión es solo marginalmente diferente a la nuestra. De acuerdo a Wright,

una condición particular fue una causa de (o contribuyó a) un resultado específico si y solo si esta fue un elemento necesario de un conjunto de condiciones reales previas que fueron suficientes para que el resultado ocurriera ${ }^{18}$.

Quizá esta idea difiere de nuestra postura en un aspecto. Wright parece requerir que todas las condiciones que pertenecen al conjunto sean antecedentes del resultado, mientras que a mí me parece que para ser suficientes para la producción de un resultado, al menos algunas condiciones pueden ser de aquellas que deben persistir hasta que el resultado ocurra. Un ejemplo de ello es la condición de un camino cubierto de hielo como factor de un accidente de tránsito.

Esta diferencia de opinión, si es que efectivamente la hay, no afecta el valor del test NESS, que es ampliamente aceptado por los teóricos de la responsabilidad extracontractual, y no solo por ellos ${ }^{19}$. Sin perjuicio de ello, Mackie no es el único en defender la noción de but-for como un análisis de afirmaciones causales singulares. En el derecho penal alemán Friedrich Toepel recientemente ha publicado una monografía sobre delitos de negligencia, los cuales

\footnotetext{
Nota de los traductores: la denominación NESS obedece a sus iniciales en inglés (Necessary Element of a Sufficient Set).

17 Wright (1985) especialmente pp. 1788-1813; WRIGHT (1988) pp. 1018-44.

18 WRIGHT (1988) p. 1019 n. 98.

19 Véase Wright (1988), p. 1019, n. 98. Para un ejemplo en el derecho penal, véase Puppe (1980) pp. 867 y sgtes.; Puppe (1987) pp. 595-6
} 
claramente tienen mucho en común con la responsabilidad extracontractual. Toepel defiende el test but-for, distanciándose de la postura mayoritaria de la doctrina alemana, que lo rechaza ${ }^{20}$.

La controversia claramente no ha terminado. En las secciones 2 y 3, exploraré algunos aspectos de la conexión causal que son compartidas por las teorías NESS y but-for, y otros aspectos en que difieren. En particular, el análisis se enfoca en determinar, por una parte, en qué medida la causalidad en la responsabilidad extracontractual depende de conceptos aplicables fuera del derecho; $y$, por la otra, en qué medida refleja consideraciones normativas, legales o morales.

\section{ELEMENTOS COMUNES DE LAS TEORÍAS NESS Y BUT-FOR}

Algunos asuntos son, o debieran ser, un fundamento común para las teorías NESS y but-for. Primero, cada una de estas teorías pretende elucidar el significado de 'condición causalmente relevante', e identificar un test que permita determinar si una condición es causalmente relevante. En otras palabras, ambas teorías son en algunas ocasiones semánticas, y en otras heurísticas. La importancia de esta distinción radica en que podemos creer que una condición fue la causa de un acontecimiento específico por el hecho de formar parte de un grupo de condiciones conjuntamente suficientes para producirlo, pero al mismo tiempo podemos ser incapaces de determinar exactamente cuáles fueron esas condiciones. De tal manera que podemos denominar a una condición de este tipo como causa, e incluso podemos considerar que fue una causa en una situación particular sobre la base

20 Toepel (1992). de las uniformidades simples observadas en la vida diaria, las cuales nos conducen a pensar que la presencia de esta condición produce una diferencia en el resultado. Podemos hacer esto a pesar de ser incapaces de especificar las condiciones INUS que se encuentran en el caso particular ${ }^{21}$. Nadie puede negar que el test but-for tiene en muchas ocasiones un valor heurístico, proporcionando un método rápido para determinar la existencia de una conexión causal. Pero ello una cuestión distinta es sostener que el test forma parte del significado de 'condición causalmente relevante' o 'causa'.

Los filósofos discuten si una conexión causal es una relación entre acontecimientos o entre hechos ${ }^{22}$. Un acontecimiento puede ser descrito de distintas formas, pero un hecho está ligado a una descripción específica. Que Bruto apuñaló a César y que lo traicionó describen el mismo acontecimiento histórico, pero que Bruto apuñaló al dictador no es el mismo hecho que el haberlo traicionado. Esta distinción tiene relevancia respecto a lo que un demandante debe probar en una demanda. En una acción de responsabilidad por la muerte de César, su viuda tendría que demostrar, primero, el hecho que Bruto apuñaló a su marido y segundo, que la muerte de César fue causada por la acción de Bruto; a pesar de que lo que hizo Bruto podría ser descrito correctamente como una traición, no sería suficiente con demostrar que Bruto traicionó a César, porque no todas las formas de traición dan lugar a una acción de responsabilidad.

Mi postura es que tanto los acontecimientos como los hechos pueden estar cau-

\footnotetext{
21 Para una postura contraria, véase Mackie (1974) pp. 54-5.

22 Mackie (1974) pp. 248-65.
} 
salmente conectados; y en el derecho, incluyendo la responsabilidad extracontractual, tanto los acontecimientos como los hechos pueden ser relevantes. Un demandante debe (1) identificar el o los acontecimientos que dan lugar a la acción de responsabilidad y (2) probar que el hecho que el demandado actuó de una manera determinada causó el daño por el cual se interpone la demanda. En este sentido, el demandante debe señalar el tiempo, lugar y personas involucradas, los cuales pueden ser descritos de muchas maneras distintas. Pero además debe demostrar que un aspecto específico de los acontecimientos en cuestión (como el hecho que el demandado conducía a exceso de velocidad) posiciona al demandado dentro de la categoría jurídica relevante, y sustenta la conclusión de que su conducta ilícita o creadora de riesgo causó el daño por el cual se demanda. El demandante debe probar que el elemento que configura la ilicitud de la conducta o que crea el riesgo indebido fue relevante para la producción del resultado dañoso que da lugar a la acción de responsabilidad.

De manera tal que si el demandante sostiene que el demandado conducía a exceso de velocidad, debe probar que el hecho de conducir a tal o cual velocidad en particular y no a la velocidad adecuada fue relevante para el hecho que el demandante sufriera tales o cuales lesiones. Sin perjuicio de que el incidente en el cual se argumenta que el demandado conducía a exceso de velocidad puede ser descrito de maneras distintas -como Dan Dawes conduciendo por Main Street, o como el ingeniero del polerón amarillo apurado para volver a casa-, estas descripciones sirven meramente para identificar el incidente en cuestión. De nuevo, si el demandante lesionado en una explosión invoca algún estatuto de responsabilidad estricta por el uso de los explosivos, deberá probar que el hecho que el demandado usara explosivos fue relevante para la producción del daño por el cual solicita reparación, a pesar de que la conducta del demandado puede ser descrita de varias otras maneras -la excavación de un mineral, o la prueba de un nuevo detonador-. El derecho se estructura sobre la base de que el demandante debe probar una conexión entre los hechos que especifican aquellas características de los acontecimientos que son tanto causal como legalmente relevantes en otros contextos.

De lo anterior se deduce que el derecho determina la forma en la cual se enmarca la pregunta acerca de causalidad. En los casos de responsabilidad por culpa, la conexión causal (Kausalzusammenhang en la terminología alemana) no puede ser separada de la conexión ilegal (o ilícita) (Rechtswidrigkeitszusammenhang); la separación de estos conceptos, planteada por algunos autores alemanes, es una fuente de error. El punto es dilucidar si una determinada conducta culposa (o una conducta creadora de riesgo que da lugar a una acción responsabilidad estricta) causó un determinado daño. En un país donde la responsabilidad por accidentes automovilísticos está sujeta a un régimen de responsabilidad por culpa, el punto desde el punto de vista jurídico será determinar si el hecho de que el demandado condujera negligentemente su vehículo (v.gr. no prestando debida atención al tránsito) causó los perjuicios. Pero en una jurisdicción en la cual los accidentes automovilísticos se rigen por un estatuto de responsabilidad estricta, el punto será determinar si el hecho que el demandado condujera su vehículo causó el daño. La respuesta a estas preguntas puede ser diferente en uno u otro caso. El hecho que el demandado 
condujera su vehículo puede haber causado el daño, pero su conducta negligente puede no haber sido causa del daño si su negligencia no hizo diferencia alguna respecto al resultado: el mismo accidente habría ocurrido igualmente en caso de haber prestado el cuidado debido. En responsabilidad extracontractual el punto no consiste en plantearse la pregunta abierta "¡cuál fue la causa de este daño?", sino “¿fue causado el daño por el hecho que el demandado se comportara de manera ilícita o creando un riesgo indebido?". La primera pregunta requiere de una explicación de cómo se produjo el daño, mientras que la segunda pregunta requiere de un análisis de la responsabilidad del demandado por la conducta descrita en categorías establecidas por la ley.

Un buen ejemplo para ilustrar esto es el caso del capitán de un barco que, a pesar de ser competente y experimentado, navega sin poseer el certificado requerido por $\operatorname{ley}^{23}$. El capitán navegó negligentemente y el barco se vio involucrado en una colisión. Los demandados admitieron que la negligencia en la navegación causó el accidente, pero negaron que la falta del permiso fuera causalmente relevante. Si hubiese sido relevante, el monto a indemnizar hubiera sido mayor. Dado que el fundamento de la responsabilidad era la culpa, la corte correctamente determinó que la falta de certificado era irrelevante, ya que de poseerlo el capitán no habría navegado de mejor manera.

A mi juicio, la falta de certificado hubiera sido causalmente relevante si hubiese sido del caso que el navegante era incompetente y que para obtener el certificado pertinente hubiera tenido que adquirir la

\footnotetext{
${ }^{23}$ Western Steamship Co. Ltd. v. NV Koninklijk Rotterdamsche Lloyd and Others (The Empire Jamaica), (1955) pp. 57-8.
}

competencia necesaria. Por otra parte, si hubiera sido aplicable un estatuto de responsabilidad estricta por navegar el barco sin certificado, de manera tal que si el barco hubiese sido navegado por un capitán sin aquel documento el riesgo de la navegación sería de cargo del demandado, en tal caso la navegación debería ser considerada como causante de la colisión. Debido a que la responsabilidad estricta no es responsabilidad por conductas ilícitas, sino responsabilidad por el ejercicio de actividades creadoras de riesgos, no habría habido necesidad en este caso de demostrar que la falta de certificado fue causalmente relevante. En un caso tal de responsabilidad estricta, hubiese bastado con demostrar que si el barco no hubiera sido navegado por $\mathrm{X}$ (que en los hechos no poseía el certificado pertinente), la colisión no se habría producido. Sin embargo, en el verdadero caso lo que explicó la colisión fue el hecho de que el barco fuera navegado negligentemente, no el solo hecho de que fuera navegado. Hay una distinción entre la conducta que cuenta como una causa en una indagación explicativa, por una parte, y la conducta que es considerada por el derecho como base de la responsabilidad por estar causalmente conectada con el daño sufrido, por la otra.

Este punto es mal entendido por Wright $^{24}$, quien piensa que los criterios de acción humana voluntaria y anormalidad (en el sentido de acciones y acontecimientos que son inusuales en determinados contextos), formulados por Hart y Honoré y utilizados para distinguir las causas de las meras condiciones causalmente relevantes, están diseñados para identificar conductas constitutivas de ilícitos ${ }^{25}$. Se nos ha critica-

\footnotetext{
24 Wright (1988) p. 1014.

25 Nuestro argumento es que los criterios están dise-
} 
do por tener problemas para acomodar la responsabilidad estricta cuando la conducta en que se basa el estatuto que la impone (por ejemplo, el uso de explosivos) puede no ser anormal o voluntaria en el sentido de haberse realizado con la intención de provocar un daño. Pero el rol de nuestros criterios es el de demarcar un límite retrospectivo en las indagaciones causales explicativas, y solo un límite prospectivo para cualquier clase de responsabilidad que corresponda de acuerdo a otros conceptos normativos del sistema de responsabilidad extracontractual. Nuestros criterios causales no son un sustituto para otros principios de la responsabilidad extracontractual que definen aquellas conductas que son ilícitas o que conllevan responsabilidad estricta. Ello depende del derecho positivo, y varía de sistema en sistema. Algunos imponen responsabilidad estricta o no imponen responsabilidad, mientras que otros insisten en exigir culpa (como en el caso de los accidentes automovilísticos). Sin embargo, es cierto que el derecho usualmente por una buena razón designa una conducta como ilícita cuando esta es realizada con el propósito de provocar daño, o cuando la conducta se desvía de una norma reconocida. De tal manera que la conducta ilícita que causa el daño frecuentemente coincide con lo que contaría como una explicación causal del daño provocado. Pero en los casos de responsabilidad estricta, donde la ilicitud de la conducta del demandado es irrelevante, no hay lugar para rastrear una ruta causal desde la ilicitud hasta el daño que sufrió el demandante.

Un tercer punto es que, independiente de la teoría que se adopte, debemos

ñados para identificar los límites de la responsabilidad en la mayoría de los casos: HarT y Honoré (1985) pp. 68-81. plantear y responder una pregunta hipotética. Esta pregunta tiene que ver con una proposición contrafáctica, la cual consiste en determinar si una condición que de hecho ocurrió no hubiera ocurrido, el resultado habría sido así y de esta forma ${ }^{26}$. De acuerdo a la teoría but-for, debemos preguntarnos si bajo las circunstancias la consecuencia igualmente habría ocurrido sin que la condición hubiera ocurrido. De acuerdo a la teoría NESS debemos preguntarnos si bajo las circunstancias la condición era un miembro necesario de un grupo de condiciones que conjuntamente son suficientes para producir la consecuencia. En este sentido, la pregunta es si las demás condiciones del grupo hubieran producido la consecuencia en ausencia de la condición en cuestión.

Pero hablar de la ausencia de una condición, o de la hipótesis de que no ocurrió, puede conducir al error. Ello sugiere que la condición que nos interesa puede ser conceptualmente eliminada y que podemos calcular lo que habría ocurrido si solo las demás condiciones hubieran estado presentes. Wright sostiene que eliminamos hipotéticamente la condición que está siendo probada sin agregar o sustraer cualquier otra condición ${ }^{27}$. Esta postura de eliminación también tiene adherentes en la teoría del derecho alemán, en parte porque los teóricos tienden a separar la conexión causal de la conexión ilícita. Si esta fuera la manera correcta de probar una hipótesis causal, ciertamente estaríamos comparando el mundo real con el imaginario. Ello porque en el mundo real la conducta es frecuentemente una elección entre varias opciones. Si John no hubiera hecho tal y tal cosa, él

\footnotetext{
26 Wright (1988) p. 1039-42.

27 WRIGHT (1988) pp. 1041-2.
} 
habría hecho algo distinto. Si no hubiera intervenido, alguien más lo habría hecho, quizá de una manera distinta. A veces estas opciones podrían haber tenido injerencia en el curso de eventos que investigamos. Mackie correctamente señala que tanto la necesidad en sentido riguroso y la suficiencia en sentido riguroso (esto es, tanto según la teoría but-for como la teoría NESS) “involucran afirmaciones acerca de qué habría pasado en el mundo si se hubiera realizado algo distinto" 28 .

Pero esto es expresado en términos más bien vagos, porque mantiene abierta la pregunta "¿qué es ese algo distinto que debemos suponer que se podría haber hecho?"29. En muchos casos la respuesta es "lo que sea que bajo las circunstancias hubiera ocurrido si la condición en cuestión no hubiera ocurrido". A veces no hay razón alguna para suponer que algo causalmente relevante habría ocurrido en tal evento, y entonces parece que la condición en cuestión simplemente se eliminó por ser causalmente irrelevante. John dejó caer un fósforo encendido en una maleza. ¿Causó John la destrucción del bosque? Para probar esto, debemos preguntarnos si el incendio del bosque habría ocurrido en caso de que John no hubiera dejado caer el fósforo encendido. Comenzamos suponiendo la contradicción de la condición, esto es, "John no dejó caer el fósforo encendido". Con frecuencia es claro que, en caso de no dejar caer el fósforo, cualquier otra cosa que no sea un incendio podría haber ocurrido. Pero la situación sería distinta si supiéramos que, en caso de que John no hubiera dejado caer

\footnotetext{
28 Mackie (1974) pp. 51-2.

29 Por las razones que se señalan en el texto, son insatisfactorias las posturas al respecto, tanto la de Wright como la de Lewis, expresada ésta en Lewis (1973) pp. 72-7.
}

un fósforo, David lo habría hecho de todas formas. En ese caso, aunque John efectivamente destruyó el bosque, destruyó algo que de cualquier manera estaba destinado a su destrucción, y ello podría afectar la demanda del dueño del bosque. Sin embargo, usualmente no hay razón para suponer tal evento alternativo, y por tanto no habría necesidad expresa de reemplazar algo por la condición eliminada.

Pero la noción de que nada se reemplaza por la condición cuya relevancia causal estamos probando es una ilusión. Supongamos que queremos probar la afirmación según la cual Churchill mantuvo a Gran Bretaña en la guerra en 1940. ¿Fue el hecho de que él fuera Primer Ministro la causa de que Gran Bretaña se mantuviera en la guerra? En este caso, no podemos eliminar a Churchill sin reemplazarlo por otro Primer Ministro cuya hipotética conducta en estos asuntos tendría influencia para determinar si Gran Bretaña se mantenía o no en la guerra. La afirmación contradictoria a "Churchill fue Primer Ministro", esto es, "Churchill no fue Primer Ministro" implicaría en el mundo de 1940 que alguien más fue el Primer Ministro (por ejemplo, Halifax); y debemos entonces preguntarnos si esta persona habría tenido la voluntad y la capacidad de convencer al Parlamento y el pueblo británico de continuar en la guerra. La afirmación causal sobre Churchill implícitamente lo compara con su hipotético reemplazante. Es cierto que en términos lógicos "Churchill no fue Primer Ministro en 1940 " es compatible con que no exista un Primer Ministro en absoluto. Pero es el mundo real y no un mundo imaginario o un cálculo lógico el que determina lo que la afirmación contradictoria de la condición en cuestión implica en el contexto, y por tanto, debiera ser también lo que determi- 
na qué debe reemplazarse por la condición para probar la proposición contrafáctica. En ese mundo real, si Churchill no hubiera sido Primer Ministro, alguien más habría ocupado ese puesto. Y tal persona podría haber mantenido o no haber mantenido a Gran Bretaña en la guerra.

En un contexto jurídico, el mismo marco teórico puede ser aplicado, excepto que cuando la indagación tiene que ver con la relevancia causal de la conducta ilícita, como es usual en las demandas de responsabilidad extracontractual, debemos reemplazar la conducta ilícita del demandado por una conducta lícita de su parte ${ }^{30}$. Cuando la responsabilidad se basa en la culpa, la comparación se realiza no con lo que habría ocurrido si el demandado nada hubiera hecho, sino con lo que habría ocurrido si este hubiera actuado adecuadamente. La razón para realizar este reemplazo es similar al caso de Churchill. La afirmación contradictoria de "el demandado actuó ilícitamente" es "el demandado no actuó ilícitamente", y esto es en términos lógicos es muy vago; por ejemplo, es compatible con que nada haya hecho. Nuevamente debemos atender a las características del mundo real $-\mathrm{y}$ en este caso, el mundo del derecho positivo de la responsabilidad extracontractual-, el cual nos señala que el no actuar ilícitamente implica actuar lícitamente. La razón por la cual este es el reemplazo adecuado radica en que el propósito de la indagación jurídica no es determinar si la conducta del demandado como tal hizo alguna diferencia en el resultado, sino en determinar si dicha diferencia se produjo por el hecho de que tal conducta fuera ilícita.

30 VV. AA., Hart y Honoré (1985) pp. lviii-lx, 411-14; Toepel (1992) p. 106.
Del mismo modo, la responsabilidad extracontractual normalmente requiere que el demandante pruebe que el aspecto ilícito de la conducta del demandado estuvo causalmente conectado con el daño ${ }^{31}$. Por ello, para eliminar la conducción a exceso de velocidad se requiere que primero reemplacemos el exceso de velocidad por la conducción a una velocidad permitida, y luego que nos preguntemos si esta conducta habría ocasionado las lesiones que de hecho ocurrieron. Más aún, la hipótesis de una conducta lícita involucra suponer no solo que el demandado conducía a una velocidad adecuada, sino también que se consideren las consecuencias probables que tal supuesto provocaría. Por ejemplo, debe considerarse si el peatón que fue atropellado habría visto el automóvil del demandado con suficiente anticipación como para evitarlo en caso que el demandado hubiera circulado a una velocidad prudente. De manera similar, si alguien distinto a Churchill hubiera ocupado el cargo de Primer Ministro sus colegas habrían sentido un menor temor a contradecirlo, y esto debe ser considerado al responder la pregunta histórica de 1940 . En la mayoría de los contextos jurídicos, la indagación hipotética requiere que todas las condiciones se mantengan constantes, con la excepción de que la conducta ilícita respecto de la cual se pretende inculpar al demandado las reemplazamos por la conducta lícita y sus consecuencias probables .

31 Este no es el caso si la ley dispone que, si el demandado actúa ilícitamente actúa a su propio riesgo. En tal evento, como en los casos de responsabilidad estricta, solo deberá probarse que la acción del demandado estuvo causalmente conectada con el daño y no que su aspecto ilícito tuvo dicha conexión causal. Hart y Honoré (1985) pp. lx-lxi. Y por supuesto hay algunos ilícitos, como el de interferencia a la propiedad privada (trespass), que no requieren probar daño. 
Sin embargo, en el contexto de la responsabilidad estricta, la indagación tiene mayor similitud con el caso del fósforo caí$\mathrm{do}^{32}$. El reemplazo de la conducta lícita no es posible y no es necesario en los casos de responsabilidad estricta, ya que a pesar de que la conducta del demandado es creadora de riesgo, no es ilícita a menos que cause daño. En tal caso la indagación hipotética debe, por tanto, consistir en determinar si el demandante habría sufrido lesiones en caso de que el demandado no hubiera realizado la actividad (por ejemplo, el uso de explosivos) que conlleva responsabilidad estricta. Normalmente no hay razón para suponer que si el demandado no hubiera empleado los explosivos para una detonación, el demandado o alguien más habría causado por otros medios un daño a la víctima en ese momento y en ese lugar.

De tal manera que tanto dentro como fuera del ámbito del derecho, el propósito de la indagación determina la forma en que debemos plantear la hipótesis que se quiere probar. El sistema de responsabilidad extracontractual define lo que cuenta como conducta ilícita o constitutiva de responsabilidad estricta, y así también determina lo que el demandante debe probar. El sistema persigue proteger a las personas de violaciones ilícitas de sus derechos y de exposiciones indebidas al riesgo. Así, para determinar si una infracción ha ocurrido, la conducta ilícita del demandado debe ser normalmente comparada con la conducta conceptualmente lícita que el demandante tenía derecho a esperar de acuerdo a las circuns-

32 El incidente del fósforo caído puede surgir en el ámbito de la negligencia en la responsabilidad extracontractual. En tal caso la comparación se realizaría entre lo que el demandado hizo y el ejercicio del cuidado debido en relación con el fósforo, por ejemplo, apagándolo antes de desprenderse de él. tancias. La pregunta es si la diferencia entre la conducta ilícita que ocurrió en el mundo real y la conducta lícita (junto con sus consecuencias probables) que imaginamos que ocurre, habría producido un resultado diferente en un mundo hipotético que se asemeja al mundo real en todos los demás aspectos. En el ámbito de la responsabilidad estricta, donde el derecho es una protección en contra de los riesgos creados por la conducta lícita de otros, la indagación causal se adapta a tal propósito.

¿Implica el hecho que en la responsabilidad extracontractual normalmente comparamos conductas ilícitas con aquellas lícitas, el que la pregunta causal esconde un carácter normativo? La respuesta es negativa, puesto que la pregunta acerca de lo que habría ocurrido en caso que el demandado hubiera obedecido una norma jurídica no es más normativa que la pregunta acerca de lo que habría ocurrido si el Primer Ministro hubiese sido otra persona que no fuera Churchill. La respuesta a estas indagaciones causales no tiene un componente normativo. Ello no cambiaría incluso si suponemos que habría sido mejor para Gran Bretaña hacer la paz en 1940, o que sería mejor, para combatir la sobrepoblación, que los automovilistas condujeran sus vehículos con los ojos vendados.

Hay quienes sostienen que las proposiciones contrafácticas no pueden ser verdaderas ni falsas ${ }^{33}$. Sin embargo, el procedimiento de responsabilidad extracontractual supone, a mi juicio correctamente, que pueden serlo. Con frecuencia, podemos saber en una determinada hipótesis lo que habría ocurrido en el mundo real. Sabemos que si frotamos un fósforo bajo ciertas circunstan-

33 VV. AA., Mackie (1974) p. 54; Toepel (1992) p. 55 . 
cias aparecerá una llama. La afirmación "si un fósforo es frotado bajo las condiciones XYZ una llama aparecerá" puede ser verdadera o falsa y su verdadero valor puede ser probado. ¿Por qué no también "si un fósforo hubiera sido frotado ... una llama habría aparecido"? La única diferencia es que la proposición acerca del pasado puede ser verificada solo indirectamente, bajo el supuesto de que bajo condiciones similares debieran ocurrir resultados similares. Este supuesto no puede ser comprobado, y a menos que esté bien fundamentado, no podemos confiar en regularidades causales o leyes científicas. Por cierto que frecuentemente no estamos seguros de lo que habría ocurrido en una situación determinada si el demandado hubiera actuado de forma lícita. Aquí, a pesar de que la proposición contrafáctica "si $\mathrm{X}$ no hubiera hecho lo que hizo, Y no habría ocurrido" es en principio verdadera o falsa, no podemos afirmar con certeza si es lo uno o lo otro. Debemos recurrir entonces a reglas jurídicas que instruyan al juez o jurado a determinar las probabilidades $y$, si es necesario, recurrir a reglas sobre carga de la prueba.

\section{NESS VERSUS BUT-FOR: LAS DIFERENCIAS ENTRE LAS TEORÍAS}

Ahora paso a ocuparme de los ejemplos que los partidarios de las teorías NESS y but-for interpretan de manera diferente. Algunos se refieren a sobredeterminación, otros a indeterminación. Como se recordará, los casos de sobredeterminación son aquellos que involucran dos o más acciones independientes, cada una de las cuales por sí sola habría sido suficiente para producir el daño. En tales casos, los procesos causales independientes pueden ser similares o diferentes, y pueden culminar en daño ya sea al mismo tiempo o sucesivamente. Cuando (1) procesos causales similares culminan al mismo tiempo en daño las teorías NESS y but-for apuntan a conclusiones causales diferentes. Pero cuando (2) los procesos causales son diferentes o (3) un proceso causal culmina en daño antes que el otro, ambas teorías señalan la misma conclusión causal. En los casos de (4) causar el que las personas actúen o de inducir a las personas para que actúen, ninguna teoría es adecuada, pero la noción de suficiencia, en una forma modificada, explica por qué tales casos son considerados como relaciones causales o cuasi causales.

A. Sobredeterminación: Procesos CAUSALES SIMILARES QUE CULMINAN AL MISMO TIEMPO

Dos procesos causales similares pueden culminar al mismo tiempo en un mismo daño. Dos disparos, efectuados en forma negligente pero independientemente por A y por B cuando ambos se encuentran cazando, alcanzan simultáneamente a $\mathrm{C}$ y destruyen su ojo izquierdo. Cada uno de los disparos era suficiente para producir este resultado sin necesidad del otro disparo, y los efectos de los dos tiros no pueden distinguirse entre sí. Ninguno de los disparos fue necesario en el sentido riguroso del butfor, pero cada uno de ellos fue necesario en el sentido débil de haber sido un integrante necesario de un grupo de condiciones conjuntamente suficientes para destruir la vista del ojo de la víctima ${ }^{34}$. Sería contraintuitivo sostener que ni A ni B son responsables por la pérdida del ojo de C. Pero, ¿son razones de política legal, o intuiciones acerca de la responsabilidad, lo que nos conduce a hacer

\footnotetext{
34 Necesidad en este sentido laxo se describe arriba. Véase arriba, el texto acompañando nn. 5-8.
} 
caso omiso de la falta de conexión causal entre cada disparo y la pérdida del ojo?

Mackie, apoyando la teoría but-for, sostiene que cuando se presenta este tipo de sobredeterminación, la causa del daño consiste en las acciones de A y B tomadas como un conjunto ${ }^{35}$. En ausencia de ambas acciones, $\mathrm{C}$ no habría perdido la visión de su ojo. No tiene sentido, piensa Mackie, preguntar cuál de ellas fue la causa. Quizás no, pero ¿por qué es necesario preguntar cuál fue la causa? ¿Acaso cada disparo no puede haber sido una causa de la pérdida de la visión del ojo en un sentido adecuado tanto para explicar lo que ocurrió causalmente como para atribuir responsabilidad a $\mathrm{A}$ y B? Pareciera que, de acuerdo a la visión de Mackie, si A y B son considerados responsables civil o penalmente, dicha conclusión debe basarse en una política legal que hace caso omiso de la falta de conexión causal, o descansar en un especial concepto legal de causa. En efecto, Mackie señala que "cualquiera que pueda ser nuestro concepto concreto de causa, es obvio que podemos construir conceptos causales como lo deseemos, lo que puede ser útil para determinados propósitos" 36 . Vale la pena averiguar, por lo tanto, si en tales casos de sobredeterminación los juristas recurren a una especial noción legal de causa.

Nuestros conceptos son herramientas configuradas por los propósitos para los cuales las utilizamos. La causalidad se utiliza principalmente para tres propósitos: para proveer fórmulas, para explicar acontecimientos y para asignar responsabilidad. Sus raíces se encuentran probablemente en el primero de dichos propósitos. Incluso los primates no humanos encuentran fór-

\footnotetext{
35 VV. AA., Mackie (1974) p. 47; Toepel (1992) pp. 71-2, 84 .

36 Mackie (1974) p. 58
}

mulas para lograr lo que ellos quieren. Para romper una nuez se necesita una piedra de cierto tamaño y peso y se debe bajar la piedra sobre la nuez con una cierta fuerza. Se aprende a elaborar lo que los sofisticados parientes de una época posterior llamarán un grupo de condiciones en conjunto suficientes para producir un resultado determinado, el rompimiento de una nuez. Habiendo ensamblado lo que parece ser un grupo de condiciones suficientes, estas se reducen gradualmente mediante la eliminación de aquellas que el ensayo y error demuestran que son innecesarias. Resulta ser necesario que la piedra sea de un cierto peso, que se emplee un cierto grado de fuerza y que la cáscara de la nuez no sea muy gruesa, siendo innecesario que el viento sople en dirección norte o que el agente profiera un alarido aterrador. La fórmula es general y se construye a través del tiempo, a medida que se acumulan los ejemplos y se ensayan las condiciones.

El descubrimiento de las condiciones que son integrantes necesarios de un grupo suficiente para producir un resultado se puede utilizar tanto para explicar acontecimientos como para provocarlos. Dicho descubrimiento se puede extender a acontecimientos sobre los cuales no tenemos control. Buscamos descubrir las condiciones de estos acontecimientos, tal vez con el fin de controlar en el futuro acontecimientos similares, o simplemente para entender cómo funciona el universo. El conocimiento así adquirido puede ser de utilidad práctica, pero también se puede buscar por su valor en sí mismo. Se puede utilizar para trazar los efectos de los acontecimientos de la naturaleza y de fuerzas inanimadas. Se puede usar también para asignar responsabilidad -responsabilidad en la vida en sociedad- a 
los seres humanos por el resultado de sus conductas.

Para todos estos propósitos -elaboración de fórmulas, explicación de acontecimientos y atribución de responsabilidadpodemos usar el concepto de integrantes necesarios de un grupo de condiciones en conjunto suficientes para producir un resultado de una determinada clase, aunque no seamos capaces de especificar o cuantificar todas las condiciones. Esta limitada capacidad para especificar las condiciones no nos impide hacer uso de ideas causales para explicar retrospectivamente los acontecimientos en términos de acontecimientos y condiciones previos; o prospectivamente, en términos de resultados, para asignar responsabilidad por una conducta. Estas no son funciones normativas. No hay diferencia alguna si el acontecimiento a explicar, o la conducta a evaluar, se juzgan buenos o malos. Es el derecho de la responsabilidad extracontractual, no el concepto de causa, el que nos invita a concentrarnos en el resultado de la conducta ilícita.

¿Qué relevancia tiene esto en el problema de la sobredeterminación? Ciertamente la lección es que el test NESS no se limita al contexto de la responsabilidad en general o del derecho de la responsabilidad extracontractual en particular. Volviendo al ejemplo de los dos disparos que, efectuados independientemente por A y por B, lesionaron el ojo de $\mathrm{C}$, cada una de las acciones de A y de B ejemplifican cómo lesionar el ojo izquierdo de $\mathrm{C}$, si ese fuera, tal vez, el objetivo de unos francotiradores en una operación militar. Cada una de esas acciones proporciona también una explicación para la pérdida del ojo izquierdo de C. Entonces, ¿por qué cada una de ellas no debería proporcionar un fundamento para asignar responsabilidad legal y moral a $\mathrm{A}$ y a B?
No se necesita recurrir a la política legal o a consideraciones normativas para arribar a la conclusión de que tanto A y B causaron independientemente el daño a C. Ninguno de los propósitos para los que se utilizan los conceptos causales nos obliga a adoptar la teoría but-for. Puede haber diferentes fórmulas para conseguir una determinada clase de resultado, encontrándose disponible más de una de ellas en una ocasión determinada. Puede haber diferentes explicaciones para un acontecimiento de una clase determinada, encontrándose presente más de una de ellas en una ocasión específica. Para impedir la construcción de una muralla de ladrillos, una fórmula es retener los ladrillos, la otra es retener la argamasa para los ladrillos. Si A retiene los ladrillos y $B$, en forma independiente, retiene la argamasa para los ladrillos y la muralla no se construye, o no se construye a tiempo, ¿acaso su construcción no ha sido impedida tanto por A como por B? No necesitamos de un especial concepto "legal" de causa para lidiar con la simultánea sobredeterminación por procesos causales similares.

En el contexto del derecho penal Toepel niega que A o B sean responsables de la lesión del ojo izquierdo de $\mathrm{C}$ en un caso como el de los disparos ${ }^{37}$. Además de señalar la presunción de inocencia, Toepel argumenta que es arbitrario ignorar el disparo de $\mathrm{B}$ cuando se está decidiendo si el disparo de A fue un integrante necesario de un grupo de condiciones suficientes para producir el daño, y viceversa. La respuesta a esta objeción es que el disparo de B puede ser provisionalmente ignorado cuando estamos considerando el grupo de condiciones de las cuales el disparo de A es un integrante, porque ese grupo puede que sea suficien-

37 Toepel (1992) pp. 66, 72-5. 
te sin el disparo de $\mathrm{B}$. Al investigar la causa de una secuencia física de acontecimientos, el procedimiento correcto es ensamblar un grupo de condiciones aparentemente suficientes para producir y, por lo tanto, explicar el resultado. Hacemos esto a la luz de lo que sabemos que son condiciones INUS de resultados de esa clase ${ }^{38}$. Pero el grupo que provisionalmente ensamblamos puede contener algunas condiciones que resultan ser innecesarias para el resultado.

Por ejemplo, el grupo provisional de condiciones podría consistir en el disparo de $\mathrm{A}$, la distancia entre $\mathrm{A}$ y $\mathrm{C}$, la fuerza del viento, el color de la chaqueta de A, y el disparo de B. Luego reducimos el grupo mediante la eliminación de aquellas condiciones que no le eran necesarias. Esto descarta el color de la chaqueta de A. Eliminamos provisionalmente el disparo de $\mathrm{B}$ no porque no fuera claramente necesario, sino porque nuestro conocimiento de las regularidades causales y de las leyes científicas nos conduce a pensar que el disparo de A puede que haya sido suficiente para lesionar el ojo de $\mathrm{C}$ sin el disparo de $\mathrm{B}$. Habiendo reducido el grupo hasta este punto, a continuación examinamos la relevancia del disparo de A (más precisamente, del hecho de que A disparó en forma negligente) por la vía de sustituir hipotéticamente el disparo negligente de A por la toma por parte de A del cuidado adecuado al disparar. Nos preguntamos si en tal evento $\mathrm{C}$ habría perdido su ojo como resultado de ese grupo de condiciones. En la negativa, el disparo negligente de A fue una causa de la pérdida de la visión del ojo de C. Pero supongamos que una cuidadosa investigación demuestra que el disparo de A erró. En ese caso el disparo de A no fue causalmente

38 Véase arriba, nn. 8-15 y el texto que las acompaña. relevante para el resultado, por lo que debemos construir otro grupo de condiciones, incluyendo el disparo de B, y examinar si el disparo de $\mathrm{B}$ fue un necesario integrante de ese grupo de condiciones que en conjunto produjeron la pérdida de la visión del ojo de C. La crítica de Toepel es que este procedimiento involucra el decidir que de hecho el disparo de A fue causalmente relevante antes que se le examine para determinar su relevancia causal ${ }^{39}$. Ello no es así. Antes de examinar el disparo de A para determinar su relevancia causal, mientras que al mismo tiempo provisionalmente omitimos el disparo de $\mathrm{B}$, todo lo que habremos decidido es que, como conocemos algunas de las condiciones INUS para que tenga lugar la pérdida de la visión de un ojo, el disparo de A podría haber sido en esta ocasión una condición causalmente relevante incluso en la ausencia del disparo de B. Es verdad que el procedimiento de verificación será posible solo si conocemos algunas regularidades causales antes de que comencemos dicho procedimiento. Pero no necesitamos asumir desde el comienzo que el resultado del examen será positivo.

Un análisis similar de sobredeterminación causal podría ser aplicado a otros casos en los que dos procesos similares parecen ser responsables de un acontecimiento, por ejemplo, cuando dos incendios se mezclan y en conjunto terminan en un resultado dañoso ${ }^{40}$, o cuando la polución creada por varias personas de manera independiente entre sí contamina un arroyo o un lago ${ }^{41}$.

\footnotetext{
39 Toepel (1992) p. 69.

40 Wright (1988) pp. 1018, 1022.

41 Véase en general Wright (1988) pp. 1035-7.
} 
B. Sobredeterminación: Procesos CAUSALES DIFERENTES

En otros casos de sobredeterminación los dos grupos de condiciones involucran procesos causales cualitativamente diferentes, tales como el envenenamiento y la deshidratación, procesos respecto de los cuales sus diferentes etapas han sido analizadas, pudiendo distinguirse el uno del otro. En tal caso, si sabemos lo suficiente acerca de las etapas por las que tuvieron lugar los acontecimientos, generalmente podemos decir, incluso en casos de sobredeterminación, cuál proceso causal mantuvo su curso y cual se frustró. Así, en el caso del viajero en el desierto ${ }^{42}$-en donde $A$ envenena el agua del barril de $\mathrm{C}$, $\mathrm{B}$ vacía el barril antes que $\mathrm{C}$ beba el agua envenenada, y $\mathrm{C}$ muere de sed- me parece ahora que $\mathrm{B}$ causa la muerte de C. Lamento que, a pesar de las críticas de Mackie ${ }^{43}$, respaldadas posteriormente por Wright ${ }^{44}$, la segunda edición de Hart y Honoré haya seguido resistiendo esta conclusión ${ }^{45}$. Pienso ahora que la conducta de $\mathrm{B}$ introduce una condición, la falta de agua, que atendidas las circunstancias, incluyendo la ausencia de otro suministro de agua, es suficiente para provocar y de hecho provoca la muerte de $\mathrm{C}$ por deshidratación.

También es verdad que $\mathrm{B}$ salvó a $\mathrm{C}$ de morir envenenado. Pero esto no es relevante en una indagación explicativa, puesto que la acción de $\mathrm{B}$ explica adecuadamente cómo ocurrió la muerte de C (a través de la

\footnotetext{
42 VV. AA., McLaughlin (1925-1926) pp. 149, 155 n. 25; Hart y Honoré (1985) pp. 239-41; МаскIE (1974) pp. 44-6.

43 Mackie (1974) pp. 44, 46-7.

44 WRIGHT (1988) p. 1024.

45 VV.AA., Hart y Honoré (1959) pp. 219-20; Hart y Honoré (1985) pp. 239-41; MaCKIE (1974) pp. 45-6.
}

deshidratación), ni debería ser relevante en una acción civil por la muerte ilícita de $\mathrm{C}$ o en un encausamiento por el delito de homicidio. Si B, sin percatarse de que el agua del barril estaba envenenada, vació el barril, ya queriendo dañar a $\mathrm{C}$ o ya incumpliendo negligentemente su deber de cuidado para con C, la viuda de C debería por ello tener éxito en una acción por la muerte ilícita ${ }^{46}$-aunque en razón de que $\mathrm{C}$ estaba en cualquier caso condenado a morir, la indemnización será mínima. Por otro lado, si B se percató de que el agua estaba envenenada y vació el barril para evitar que $\mathrm{C}$ bebiera el agua envenenada, y suponiendo que otro suministro de agua podía ser encontrado a tiempo para salvar a C, aún así B habría involuntariamente "causado" la muerte de C; pero no sería legalmente responsable por ello. No hay necesidad de proponer ningún especial concepto legal de causa para entender este tipo de caso.

En los casos de sobredeterminación, en donde diferentes procesos causales se asocian con las dos condiciones que son candidatas causales, no debería haber necesidad alguna de demostrar que una de ellas fue una condición NESS de la muerte tal y cómo la muerte ocurrió (p. ej. por deshidratación el martes, en vez de que por envenenamiento el lunes $)^{47}$. Eso sería para exigir el establecimiento del preciso punto en discusión, a saber, cómo ocurrió la muerte de la víctima. Lo que se tiene que probar en una acción de responsabilidad extracontractual es que el acto ilícito del demandado causó el daño, en este caso la muerte de la víctima. A partir de la forma en que el dere-

\footnotetext{
$46 \mathrm{Y}$, si el daño fue intencional, B será culpable de homicidio.

47 Como lo sugiere Mackie (1974) p. 46. Véase también Toepel (1992) pp. 70, 78-9.
} 
cho estructura las acciones por una muerte ilícita, sabemos que lo que es legalmente relevante es la muerte, no la muerte en este o aquel tiempo, o por medio de este o aquel proceso $^{48}$. Sin embargo, la parte demandante (la viuda) tiene que identificar la muerte por la que pretende reparación. Esto exige que la víctima, el tiempo y el lugar sean especificados. Ella también tiene que demostrar que el acto ilícito del demandado causó la muerte, lo que involucra demostrar que la produjo algún proceso causal iniciado por el demandado. En el ejemplo del barril de agua, es relevante que la conducta de B (vaciar el barril de agua) fuera una condición de la muerte por deshidratación de $\mathrm{C}$ porque el proceso de deshidratación conecta la acción de $\mathrm{B}$, a través de una serie de etapas, con la muerte de C. Es relevante establecer que este proceso ocurrió porque, atendida la pluralidad de las causas posibles de muerte, es necesario para la viuda de C señalar un proceso causal específico que vincule la conducta de $\mathrm{B}$ y la muerte de $\mathrm{C}$, y tal proceso es el de la deshidratación.

\section{Sobredeterminación: DaÑo QUe YA HA OCURRIDO}

Aunque los filósofos puedan discutir la posibilidad de una causación retroactiva parece claro que es imposible causar un acontecimiento que ya ha ocurrido. Se puede azotar a un caballo muerto pero no se puede matar mediante azotes a un caballo ya muerto*. Por otro lado, se puede causar

48 VV.AA., Wright (1985) pp. 1777-8; Wright (1988) pp. 1025-26; Puppe (1980) pp. 863, 867-8.

* Nota de los traductores: El autor hace un juego de palabras con la frase "to flog a dead horse", que literalmente significa "azotar a un caballo muerto" y que en el idioma inglés consiste en una popular expresión de sentido figurado. Dicha expresión se utiliza para referirse en general a determinadas conductas o si- la muerte a alguien al que solo le resta una instante por vivir, como en el caso en el que se acusó a los demandados de haber electrocutado a un niño en el momento en que este se precipitaba a una muerte segura ${ }^{49}$. El hecho de que nuestro concepto de causa no admita la causación de un daño que ya ha ocurrido puede dar origen a un problema de sobredeterminación cuando el daño consiste en privar a alguien de oportunidades futuras.

Supóngase que A negligentemente lesiona a $\mathrm{C}$, un luchador de lucha libre, de manera que este queda incapacitado de por vida para practicar la lucha libre. Seis meses más tarde, $\mathrm{B}$, independientemente $\mathrm{y}$ en forma negligente, atropella a $\mathrm{C}$ de modo que este no habría podido practicar lucha libre en el futuro aún si no hubiese sido lesionado la primera vez. El que la acción de B fuera independiente implica que la primera lesión no contribuyó a la segunda, por ejemplo, impidiendo a $\mathrm{C}$ evitar el atropello ${ }^{50}$.

¿En qué posición queda la demanda de $C$ por la pérdida de ingresos futuros como luchador de lucha libre? A, y solo $\mathrm{A}$, es claramente responsable por lo que $\mathrm{C}$ habría ganado en los seis meses siguientes a la primera lesión. Sin embargo, en lo que respecta a los ingresos de la lucha libre perdidos por $\mathrm{C}$ con posterioridad a la segunda lesión, la responsabilidad es mucho menos clara. B alegará que no causó la incapacidad

tuaciones que, en las circunstancias, son consideradas absolutamente inútiles. Así, el insistir en discutir algo que a nadie le interesa o que ya ha sido totalmente discutido o destinar el tiempo intentando lograr algo que se entiende prácticamente imposible de lograr, es descrito como "azotar a un caballo muerto".

49 Dillon v. Twin State Gas \& Elec. Co. (1932).

50 Los hechos se sugieren en Baker v. Willoughby (1969). Cf. Jobling v. Associated Dairies (1981). 
de C para practicar la lucha libre ni siquiera en parte, puesto que $\mathrm{C}$ ya se encontraba permanentemente discapacitado. Incluso más, A alegará que su responsabilidad se limita solo a los ingresos correspondientes a dichos seis meses puesto que en todo caso, parece claro, $\mathrm{C}$ no habría podido practicar la lucha libre por más de dicho período. Si se aceptan ambos argumentos, C, habiendo sido ilícitamente lesionado en dos ocasiones, obtiene menos que si hubiese sido lesionado solo una vez, lo cual es insatisfactorio. Con todo, este caso no es como el de la simultánea sobredeterminación, donde se puede decir con propiedad que cada agente ha causado la misma lesión. Alguien que reclama haber perdido oportunidades futuras para ganar dinero debe demostrar que, en ausencia del acto ilícito del cual reclama, habría podido aprovechar aquellas oportunidades. Por ejemplo, si después de los seis meses $\mathrm{C}$ hubiese muerto de un ataque cardiaco no provocado por la lesión causada por A, sus herederos no podrían reclamar lucro cesante por el período posterior a su fallecimiento. Un cadáver no puede practicar lucha libre, y no hay razón para imponer sobre $\mathrm{A}$ el riesgo de que $\mathrm{C}$ podía morir por causas naturales no relacionadas con la acción ilícita de A.

Existen dos posibles alternativas para superar la referida dificultad, una de las cuales es consistente con los principios causales mientras que la otra se apoya en un fundamento relativo a la distribución del riesgo. La primera solución consiste en sostener que hay una causa de acción en responsabilidad extracontractual cuando mediante una acción ilícita se priva a otra persona de una reparación en el ámbito de la responsabilidad extracontractual que de otra forma habría estado disponible para ella. En el caso del lesionado luchador de lucha libre, $\mathrm{B}$ ha privado a $\mathrm{C}$ de una acción en contra de A para la reparación en responsabilidad extracontractual de la pérdida de sus ingresos provenientes de la lucha libre con posterioridad a la segunda lesión. Esta causa de acción, si existiera, sería como aquella que se sugiere como recurso legal, muy discutido actualmente, en contra de aquel que ilícitamente priva de una oportunidad a otra persona ${ }^{51}$. La solución alternativa para resolver el dilema del lesionado luchador de lucha libre es considerar a $\mathrm{A}$ como garante de que $\mathrm{C}$ no sea privado de su posible recurso por la pérdida de ingresos causada por una posterior acción ilícita de una tercera persona. Concebir tal garantía es proporcionar un fundamento no causal para la responsabilidad, un ejemplo del conocido principio con arreglo al cual el riesgo de daño a $\mathrm{C}$ se impone algunas veces sobre A. Aquí el riesgo se estaría imponiendo sobre A como resultado del ilícito de A, tal como en la compraventa el riesgo es algunas veces de cargo del vendedor en razón de su incumplimiento consistente en no entregar oportunamente la cosa vendida. La justificación para imponer el riesgo sobre A sería sostener que es función del derecho proteger a las personas en contra de interferencias ilícitas de sus derechos. En lugar de permitir que una persona que ha sufrido dos ilícitos sea privada de un recurso legal, es mejor establecer que el autor del primer hecho ilícito sea su garante en contra de las consecuencias económicas de un hecho

\footnotetext{
51 Wright (1988) pp. 1067-72. Un caso de "pérdida de oportunidad" puede surgir, por ejemplo, si un médico negligentemente omite diagnosticar oportunamente una enfermedad progresiva tal como un cáncer, y de esta manera priva a un paciente de, digamos, un veinte por ciento de oportunidades de recuperación. Causas de acción en estos términos, cualesquiera que sean sus méritos intrínsecos, no violentan los principios causales.
} 
ilícito posterior cometido por una tercera persona. Hacer esto no sería introducir un especial sentido jurídico de causa. Sería sustituir la responsabilidad basada en la causación de un daño, por la responsabilidad basada en la distribución del riesgo.

\section{INDETERMINACIÓN}

La indeterminación presenta una dificultad a la teoría NESS. Si el mundo es indeterminado, no podemos ensamblar un grupo de condiciones invariablemente suficientes para producir un resultado determinado. Puede que el resultado usualmente se produzca, pero habrá ocasiones en que no se producirá. A lo sumo, puede que haya una cierta probabilidad de que en una ocasión determinada el resultado se producirá. Un mundo indeterminado también presenta una dificultad a la teoría but-for, por cuanto en un mundo indeterminado no podemos calcular exactamente lo que habría ocurrido en la ausencia de una particular acción ilícita. Pero, según Mackie, si podemos recurrir a nuestra intuitiva comprensión de las relaciones but-for ${ }^{52}$, la dificultad es menos seria para la teoría but-for que para la teoría NESS.

Mackie, aunque dejando abierta la cuestión de si el mundo es realmente indeterminado, argumenta que lo que diríamos con respecto a la causación en un mundo indeterminado apoya la teoría but-for ${ }^{53}$. Este autor imagina dos máquinas de caramelos, ambas "indeterministas" ${ }^{4}$. Una de ellas nunca produce caramelos a menos que se inserte la moneda correcta, pero no siempre produce caramelos cuando se inserta dicha moneda. La otra máquina siempre

\footnotetext{
52 Véase, arriba, el texto acompañando n. 15.

53 Toepel (1992) pp. 61, 90-5.

54 Mackie (1974) pp. 40-3, 47.
}

produce caramelos cuando se inserta una moneda, pero algunas veces los produce sin una moneda. Aplicando el test but-for, Mackie piensa que respecto de la primera máquina sostendríamos que ella ha causado la aparición del caramelo cuando este sí ha aparecido, pero que esto lo rechazaríamos respecto de la segunda máquina.

El argumento de Mackie no es convincente $^{55}$. Si pensáramos que el mundo de las máquinas de caramelos fuera indeterminado no tendríamos razón para suponer que la primera máquina no se comportaría en el futuro como la segunda máquina y que produciría caramelos sin que se insertara una moneda, y viceversa con respecto a la segunda máquina. No tendríamos razón para sostener que la inserción de la moneda sí causó el que apareciera el caramelo en la primera máquina pero no en la otra máquina. Pero, aunque su operación pudiera ser errática, creemos que las máquinas de caramelos son deterministas ${ }^{56}$. Explicamos su anormal comportamiento sobre la base de que, si la máquina no produce caramelos cuando se inserta una moneda o bien los produce cuando no se inserta una moneda, el mecanismo es defectuoso. En el primer caso, un factor neutralizador se encuentra presente; algo se ha atascado en la máquina e impide que salga el caramelo. Recuérdese que en la mayoría de los grupos de condiciones conjuntamente suficientes, una condición es la ausencia de condiciones neutralizadoras ${ }^{57}$. En el segundo caso, dada la pluralidad de causas, concluimos que está presente un grupo alternativo de condiciones INUS para la producción del caramelo,

\footnotetext{
55 VV. AA., Hart y Honoré (1985) pp. xl-xli, 235 n. 56; Wrigth (1988) p. 1029; Wright (1985) pp. 1777-8). Cfr. Toepel (1992) pp. 92-3.

56 Wright (1988) p. 1029.

57 Véase arriba, nn. 11-12 y el texto que las acompaña.
} 
el cual podría consistir por ejemplo no en insertar una moneda sino en dar a la máquina una fuerte patada cuando el mecanismo se atasca.

El argumento de un imaginado mundo indeterminado no apoya la teoría del but-for. ¿Qué hay del argumento de que el mundo realmente es indeterminado? La indeterminación a un nivel micro asociada con la mecánica cuántica no está en discusión. Como cuidadosamente observa Wright, ello podría ser un obstáculo para las acciones a nivel de partículas fundamentales, pero no afecta a los fenómenos macro que son la preocupación del derecho. Más desconcertante es la dificultad de trazar una conexión causal, o algo similar a ello, en el caso de acciones humanas ejecutadas por determinadas razones -cuando una persona provee a otra de una razón para hacer esto o lo otro ${ }^{58}$-. Aunque hasta ahora hemos discutido secuencias físicas de acontecimientos como si estos tuvieran lugar sin ser perturbados por la intervención humana, en la práctica hay pocas situaciones en el derecho de la responsabilidad extracontractual en donde una secuencia física de acontecimientos no se encuentra parcialmente determinada por decisiones humanas tomadas a la luz de cómo se desarrolla una situación. Por poner un ejemplo, adaptado de Mac$k e^{59}$, supóngase que la cuestión es si la declaración de Alec causó el que Bill golpeara a Charles. Si Alec dijo, por ejemplo, que

\footnotetext{
58 Hart y Honoré (1985) pp. 51-61. Por razones de espacio no me ocupo en este artículo de la provisión de oportunidades que otra persona explota o del suministro de ayuda que otro aprovecha. Estos casos son importantes legalmente y en la vida diaria pero son todavía más lejanos de las secuencias físicas que lo que lo es el actuar sobre la base de una razón proporcionada por otro.

59 MACKIE (1974) p. 43
}

Charles estaba teniendo una aventura con la novia de Bill, sería inteligible el señalar que lo que él dijo causó el que Bill golpeara a Charles. Si se objeta el uso de "causó" en un contexto en donde Bill debería haberse controlado a sí mismo, otras expresiones tales como "condujo", "indujo", y "provocó" podrían reemplazarla. Es un tipo de situación que surge con frecuencia en el derecho de la responsabilidad extracontractual, por ejemplo en relación con declaraciones falsas que inducen a otros a invertir dinero o con incitaciones que conducen a las partes contratantes a incumplir sus contratos. ¿Cómo deberían analizarse las secuencias de este tipo, que involucran el proveer de razones en base a las cuales otros actúan?

Parece imposible suponer un grupo de condiciones NESS que en conjunto serían suficientes para producir el asalto de Bill sobre Charles. Muchas personas creen que la conducta humana no está estrictamente determinada. En tal caso, no se puede ni siquiera en principio ensamblar un grupo de condiciones suficientes para inducir a una persona a actuar en una manera particular. Aún si la acción humana es determinada, no será posible todavía ensamblar un grupo de condiciones de este tipo. Ello no solo porque las reacciones de los seres humanos sean distintas. Una dificultad mayor es que una persona que ha sido enfrentada a un similar grupo de condiciones en el pasado puede, a la luz de esa experiencia, reaccionar en forma diferente en esta ocasión. No se deduce de la reacción de Bill en esta ocasión que él reaccionaría similarmente si en otra ocasión se le dijera lo mismo. De dicha reacción no se deduce que David reaccionaría en la misma forma si Alec le dijera lo mismo acerca de su novia (la novia de David). Aún con una gran cantidad de información acerca del carácter y 
antecedentes de las personas, sus reacciones simplemente no son totalmente predecibles. Además, cualquier predicción, si fuera conocida por la persona respecto de la cual la predicción se hace, podría proveer de una razón para reaccionar en forma diferente.

Por consiguiente, el determinismo en relación a la conducta humana, incluso si fuera cierto, no se puede probar. Sin embargo, la reacción de Bill es explicada por lo que Alec le dijo, y en la misma medida funciona como una explicación causal (o cuasi causal). Lo que Alec dijo fue en cierto sentido suficiente de acuerdo a las circunstancias para conducir a Bill a reaccionar en la forma que lo hizo. Sin embargo, si vamos a hablar de "causar" el que las personas actúen o bien, más modestamente, de influenciarlas en sus decisiones, se requiere una explicación diferente de la conexión.

Mackie piensa que nuestra actitud hacia las transacciones interpersonales favorece la teoría but-for ${ }^{60}$. Si Alec no hubiese dicho lo que dijo, podemos estar seguros de que Bill no hubiese golpeado a Charles. Pero, ¿por qué podemos decir esto? Presumiblemente porque hemos ensamblado, a partir de nuestra experiencia y de la de otros, no unos sets de condiciones INUS relativas al comportamiento humano, sino que algunas generalizaciones vagas que nos señalan en qué tipos de razones se basan las personas para actuar. En el presente caso la única razón que podría explicar el ataque por parte de Bill fue lo que Alec le dijo. Si Bill admite que por esto fue por lo que golpeó a Charles, se confirma el pronóstico.

Pero esto no es suficiente para demostrar que la teoría but-for explica el tipo de conexión involucrada en el actuar movido por una razón. Porque con frecuencia

${ }^{60}$ Mackie (1974) pp. 121-6. una persona tiene dos o más (normalmente muchas más) razones para llegar a una decisión y actuar en base a ella. Puede que un potencial inversionista sea influenciado por una declaración falsa en un folleto relativo a un proyecto de inversión y por el asesoramiento de su corredor de bolsa. Supóngase que por estas dos razones el inversionista efectúa una desafortunada inversión en las minas Eldorado. Me parece que nada depende de si cada una de las razones fue necesaria o suficiente para persuadirlo a invertir, o para disuadirlo de cambiar de opinión ${ }^{61}$. ¿Concluiríamos que la declaración falsa no lo indujo a hacer la inversión si el asesoramiento del corredor de bolsa fue también suficiente para persuadirlo de hacer dicha inversión? Si el inversionista está dispuesto a admitir en verdad que cada una de dichas razones lo influenció, parece irrelevante si él está dispuesto a admitir el que, si no hubiese sido por una de esas razones, no habría arribado a la decisión que tomó. Las razones sobre la base de las cuales él actúa son precisamente eso -las razones que, ya sea individual o conjuntamente, le parecieron suficientes y lo motivaron para tomar una decisión y actuar-.

A Sam se le ofrece un cargo en Middletown con un mayor sueldo. Middletown es la ciudad natal de su cónyuge y ella desea retornar allí. Puede que ambos factores -el aumento de sueldo y los deseos de su cónyuge- sean razones suficientes para inducir a Sam a aceptar la oferta, en cuyo caso ninguna de ellas es una razón but-for. O puede que ambas razones sean elementos necesarios en un grupo de razones en conjunto

${ }^{61}$ Véase Australian Steel \& Mining Corp. v. Corben (1974) p. 209; Hart y Honoré (1985) p. 193. Compárese, para el derecho penal, la sentencia de 24 de febrero de 1959 del Entscheidungen des Bundesgerichtshofes in Strafsachen; contra Toepel (1992) p. 93. 
suficientes para persuadir a Sam de aceptar la oferta. En cualquier caso, Sam actúa sobre la base de esas dos razones, las que son suficientes para persuadirlo, ya sea por separado o conjuntamente. Pero junto con estas razones que lo indujeron para trasladarse a Middletown, habrá otras condiciones tales que, si ellas no hubiesen existido, él habría rechazado la oferta. En Middletown hay buenos colegios para los niños; Middletown tiene un animado orfeón. Si no hubiese habido buenos colegios y un animado orfeón Sam habría rechazado la oferta; pero ellas no fueron sus razones para aceptar. En lo que a dichas razones se refiere él también podría solo haberse quedado en donde estaba. Con frecuencia las razones but-for no son razones para tomar una decisión o para actuar en base a ellas, sino que son razones en contra de la no toma de dicha decisión. Ellas no causan, conducen, inducen o motivan a Sam a trasladarse, no más que lo que la existencia del sistema capitalista induce al inversionista a colocar su dinero en las Minas Eldorado.

Me parece que arribamos a nuestras conclusiones acerca de lo que causó, indujo, persuadió, o provocó a alguien a actuar en la forma que lo hizo, en una manera en cierta forma similar pero no idéntica a la manera en que arribamos a conclusiones en relación a las causas de los acontecimientos físicos. No podemos construir condiciones INUS y condiciones NESS para situaciones en las que los seres humanos toman decisiones y actúan sobre la base de ellas. Pero sabemos lo suficiente acerca de las clases de razones que nos motivan, como para ser frecuentemente capaces de concluir que ciertos factores fueron individualmente o en conjunto suficientes para la toma de la decisión. Todo lo que en este contexto se quiere decir por medio de "suficiente" es que dichos factores proveen de una adecuada explicación de la decisión, y que la persona que toma la decisión debería reconocer, si es veraz, que esas fueron sus razones. Ellas fueron suficientes para este individuo en esta situación, aunque ello no implica que serían suficientes para él o para alguien más en una situación similar en una ocasión diferente. Lo que queremos decir cuando hablamos de "inducir", "persuadir", etc., es hacer referencia a las razones que a esta persona le parecieron adecuadas en esta ocasión y, por lo tanto, sobre la base de las cuales actuó. Algunas o todas ellas pueden también haber sido necesarias para la decisión; y con frecuencia es un buen procedimiento el preguntar heurísticamente si se habría arribado a la misma decisión en la ausencia de una determinada razón. Pero la respuesta a esta cuestión no es decisiva para determinar la existencia de una relación causal o cuasi causal entre razón y acción. En las transacciones interpersonales, aparte de la conducta de aquel del que se dice que la ha inducido a actuar, el que la respectiva persona no habría actuado en la forma que lo hizo no forma parte del significado de "causa", "induce", etc. El significado de conexión causal o cuasi causal es aquí más cercano a suficiencia que a necesidad, pero suficiencia no en el sentido en el que el término se utiliza en relación a las secuencias físicas, sino que más bien en el sentido de lo que alguien considera, según las circunstancias, como un motivo adecuado sobre el cual decidir y actuar.

\section{CONCLUSIONES}

¿Por qué la causalidad es importante en el derecho de la responsabilidad extracontractual? Una razón es que el insistir en la conexión causal entre conducta y daño asegura 
el que en general solo imponemos responsabilidad sobre quienes, al intervenir en el mundo, han alterado para mal el curso de los acontecimientos. Pero, ¿qué es alterar para mal el curso de los acontecimientos? ¿Es hacer (1) algo tal de manera que, bajo las condiciones predominantes, el daño ocurre? ¿O es hacer (2) algo en cuya ausencia el daño no habría ocurrido? La primera interpretación es la de la teoría NESS (para las secuencias físicas); y una variante de esa teoría se puede utilizar para explicar lo que es el influenciar decisiones y acciones humanas. La segunda interpretación es la de la teoría but-for.

La primera interpretación es preferible. Causar un determinado resultado dañoso significa, en relación a los acontecimientos físicos, completar un grupo de condiciones suficientes para producirlo, esto es, proveer una condición NESS de ese daño. En relación con el influenciar una acción humana, significa proveer de una razón que el agente humano acepta, a menudo junto con otras razones, como suficiente para inducirlo a decidir y actuar en la forma que lo hace (en su perjuicio o en el de alguien más).

Por otro lado la teoría but-for, aunque un recurso heurístico útil, proporciona intuitivamente la respuesta equivocada en ciertas áreas de la sobredeterminación y de la indeterminación. La explicación de esto parece ser que nuestro concepto de causa deriva finalmente de nuestra búsqueda de fórmulas para producir los resultados que queremos. Buscamos grupo de condiciones que sean suficientes (o, en el caso de decisiones humanas, que puedan ser consideradas suficientes por el agente) para producir un cierto resultado. El conocimiento de estos sets de condiciones, aunque casi siempre imperfecto, tiene varias aplicaciones. En particular, a menudo nos permite explicar acontecimientos confusos y, en varios contextos jurídicos, incluyendo el derecho de la responsabilidad extracontractual, fijar los límites externos de la responsabilidad por la conducta en la vida en sociedad.

Ello no hace que el concepto de causa sea un concepto normativo. El mismo concepto de causa se utiliza para descubrir fórmulas, para explicar acontecimientos, y para asignar responsabilidad por los resultados. Los elementos normativos son suministrados por el derecho sustantivo de la responsabilidad extracontractual, el cual define la conducta que conlleva o puede conllevar responsabilidad, y prescribe cuándo se debe probar la conexión causal entre la conducta y el daño.

\section{BIBLIOGRAFÍA CITADA}

Hart, H.L.A. y Honoré, A.M. (1959): Causation in the Law (Oxford Clarendon Press).

Hart, H.L.A. y Honoré, A.M. (1985): Causation in the Law (Oxford Clarendon Press, segunda edición).

Lewis, David (1973): Counterfactuals (Blackwell).

Mackie, John (1974): The Cement of the Universe. A Study of Causation (Oxford University Press).

Marc-Wogau, Konrad (1962): "On Historical Explanation”, Theoria, vol. 28: 213-33.

McLaughlin, James A. (1925-1926): "Proximate Cause", Harvard Law Review, vol. 39, $\mathrm{N}^{\circ}$ 2: 149-199.

Puppe, Ingeborg (1980): "Der Erfolg und seine kausale Erklärung im Strafrecht", Zeitschrift für die gesamte Strafrechtswissenschaft, vol. 92: 863-911.

Puppe, Ingeborg (1987): "Die Beziehung zwischen Sorgfaltswidrigkeit und Erfolg 
bei den Fahrlässigkeitsdelikten", Zeitschrift für die gesamte Strafrechtswissenschaft, vol. 99: 595-616.

Toepel, Friedrich (1992): Kausalität und Pflichtwidrigkeitzusammenhang beim fahrlässigen Erfolgsdelikt (Dunken \& Humblot).

Wright, Richard (1985): "Causation in Tort Law”, California Law Review, vol. 73, N6: 1735-1828.

WRIGHT, Richard (1988): "Causation, Responsibility, Risk, Probability, Naked Statistics, and Proof: Pruning the Bramble Bush by Clarifying the Concepts", Iowa Law Review, vol. 73: 1001-1077.

\section{JURISPRUDENCIA CITADA}

Australian Steel \& Mining Corp. v. Corben (1974): New South Wales Court of Appeal, 19742 N.S.W.L.R. 202
Baker v. Willoughby (1969): House of Lords, 26 de noviembre de 1969, [1970] A.C. 467

BGH Gr. Sen. St., 13 Entscheidungen des Bundesgerichtshofes in Strafsachen (1959): Sentencia de 24 de febrero de 1959, [BGHSt] 15 (F.R.G.)

Dillon v. Twin State Gas \& Elec. Co. (1932): 163 Atl. 111

Jobling v. Associated Dairies (1981): House of Lords, 25 de junio de 1981, [1982] A.C. 794 .

Western Steamship Co. Ltd. v. NV Koninklijk Rotterdamsche Lloyd and Others (The Empire Jamaica) (1955): Willmer J., Probate Divorce \& Admiralty Division, 27 de enero de 1955, [1955] P. 52. 
